\title{
Relative Thickness of Lead, Concrete, and Steel Required for Protection Against Narrow Beams of X-Rays
}

\author{
By George Singer,* Harold O. Wyckoff, and Frank H. Day
}

\begin{abstract}
The lead equivalents of $\mathrm{X}$-ray protective barriers are given for both concrete and steel for potentials between 200 and $1,400 \mathrm{kv}$. These were determined experimentally using a pressure ionization chamber and an X-ray tube to which constant potential was applied. Narrow X-ray beams were used. The data obtained are compared with those published by other workers. Data on the relative masses referred to lead of both concrete and steel barriers are included. The agreement among the several laboratories is satisfactory when consideration is given to differences in the test specimens used and in the experimental technic.
\end{abstract}

It is the purpose of this paper to present experimental data on the relative thickness of lead, concrete, and steel needed for protection against narrow beams of X-rays generated by potentials between 200 and $1,400 \mathrm{kv}$ and to compare these with similar results published by other laboratories. The total range so covered is 70 to 2,000 kv. The usefulness of such data depends upon the availability of information on the thickness of lead required for protective barriers. The American Standards Association Code Z54.1 [1] ${ }^{1}$ contains such recommendations for potentials up to $250 \mathrm{kv}$. Details of the research leading to the recommended absorption curves for $\mathrm{X}$-rays are given in other papers $[2,3]$. Wide-angle X-ray beam absorption in concrete is also given for 1,000 and 2,000 kv. Other technical publications contain limited absorption-curve data for potentials up to approximately $2,000 \mathrm{kv}$ as well as some data on the lead equivalent of various building materials [ 4 to 11 , incl.].

\section{Introduction}

Concrete and steel have become important as materials for the construction of X-ray protective barriers; both are now used extensively to supple-

\footnotetext{
* Deceased.

${ }_{1}$ Figures in brackets indicate the literature references at the end of this paper.
}

Protection Against Narrow Beams of X-Rays ment metallic lead and its compounds in installations for X-rays generated by potentials up to approximately $400 \mathrm{kv}$ and to replace, in large part, lead and its compounds in protective barriers for $\mathrm{X}$-rays generated by voltages above this value. This trend, given additional impetus by war conditions that have made the procurement of metallic lead difficult and the construction of metallic barriers costly, is firmly established and is unlikely to be reversed as there are sound economic reasons to justify it. As the penetrating power of X-radiation is increased up to about $3,000 \mathrm{kv}$, the effectiveness of materials of relatively low effective atomic number-such as concrete, or steel-increases also; unlike lead, these materials do not require costly supporting structures. Most high-voltage $\mathrm{X}$-ray installations are housed in new buildings of steel and concrete construction; the walls, ceilings, and floors in such buildings can be made adequately protective at relatively little additional cost by increasing their thickness sufficiently.

None of these papers covers the whole range of $\mathrm{X}$-ray quality now commonly used in the medical and industrial applications; they are widely scattered in the literature, appearing in both English and German, and in scientific and technical journals to which designers of X-ray equipment and X-ray installations do not have ready access. 
Often protective barriers are located quite near the personnel that they are to protect, and the barriers are irradiated by X-rays over large areas. The new data presented in this paper do not apply under such conditions. Only when the barrier is located far from the personnel to be protected and the irradiated area is small should this new information be used. It has been theoretically predicted and experimentally verified that the difference in apparent absorption should be perceptible in the region where scattering is appreciable. In section $\mathrm{IV}-2$ attention is called to some measurements that give the order of magnitude of this difference expressed in terms of the lead equivalent.

\section{Test Specimens}

Singer, Taylor, and Charlton [9] have reported that for narrow X-ray beams generated by potentials from 200 to $400 \mathrm{kv}$ the lead equivalent of a concrete barrier is proportional to its density and is, for practical purposes, unaffected by the nature of the concrete mix, except as the composition affects the density of the concrete. Tests made in connection with the present study - the results of which are presented in a later sectionconfirm this finding for X-rays generated by potentials up to $1,400 \mathrm{kv}$ for concrete and steel. As the lead equivalents of concrete barriers of different composition but of the same density are the same, it is sufficient to confine attention to specimens of but a single composition. Accordingly, only one concrete mix was examined. The specimens used are those described in reference
[9]. Three sizes of concrete cylinders were used. Of these, the first is $15 \mathrm{~cm}$ in diameter and $11 \mathrm{~cm}$ in length; the second, $20 \mathrm{~cm}$ in diameter and 16 $\mathrm{cm}$ in length; and the third, $20 \mathrm{~cm}$ in diameter and $22 \mathrm{~cm}$ in length. The volume ratio of cement to sand to gravel is $1: 2.2: 3.8$. Although the density of these specimens varies from 2.34 to $2.40 \mathrm{~g} / \mathrm{cm}^{3}$, all data relating to them have been corrected so as to apply to concrete of density $2.35 \mathrm{~g} / \mathrm{cm}^{3}$, that is, concrete weighing approximately $147 \mathrm{lb} / \mathrm{ft}^{3}$. For further details, the original paper should be consulted.

The steel specimens consist of $30-\mathrm{cm}$ squares of cold-rolled steel approximately $1.27 \mathrm{~cm}$ thick of density $7.8 \mathrm{~g} / \mathrm{cm}^{3}$.

\section{Method}

The method used in determining the lead equivalent of all specimens is essentially that described in the paper by Singer, Taylor, and Charlton [9]. It consists in comparing the X-ray attenuation due to each specimen with that due to each of a series of lead sheets of known thickness. This is done by measuring the relative ionization in a pressure ionization chamber when each specimen is used as a filter under identical operating conditions. The apparatus used is shown in figure 1. The X-ray generator has been described by E. E. Charlton and H. S. Hubbard [12]. This consists of a constant-potential power supply and a pumped X-ray tube made up in 10 sections. Power is supplied to the generator from a synchronous motor-generator set, the output voltage of which is remotely controlled by vary-

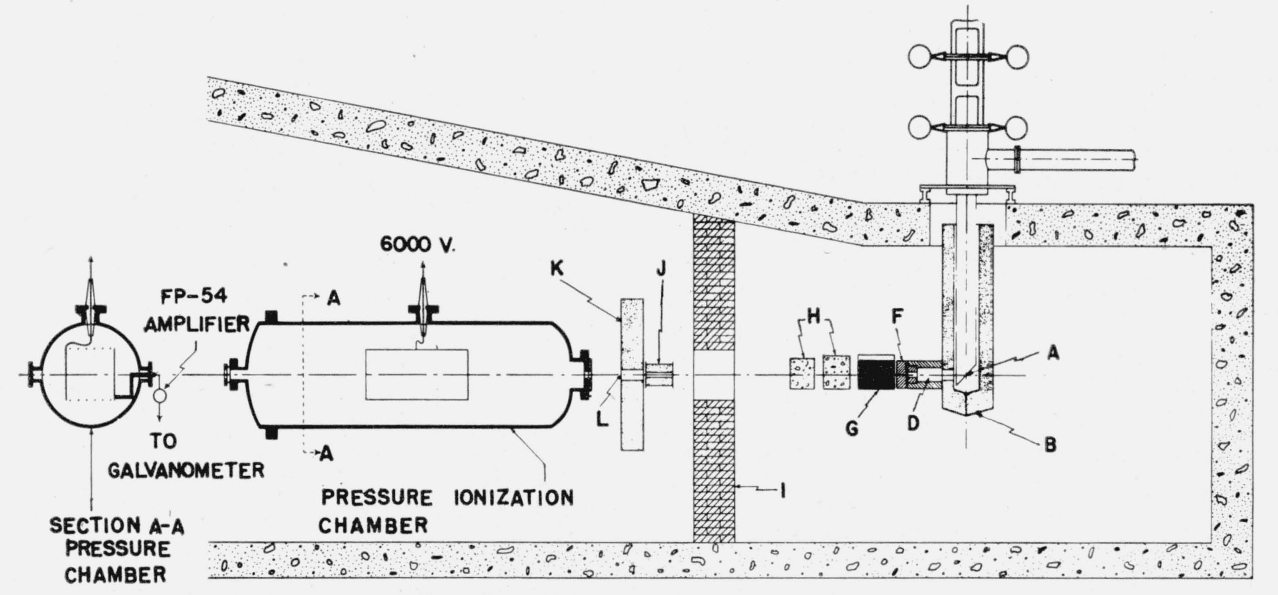

FrguRe 1.-Cross section of apparatus used in determination of lead equivalent of concrete and steel. 
ing the resistance in series with the generator field winding. The constant potential applied to the tube is measured by means of a potentiometer used in conjunction with a wire-wound resistor of 1,400 megohms in parallel with the tube and its supply. It is conservatively estimated that by means of this voltmeter the tube voltage can be measured with an accuracy of better than 1 percent. As this voltmeter is a modification of the type described by Taylor for lower voltages, his paper [13] should be consulted for further details. The tungsten target of the X-ray tube is of the reflection type, that is, the axis of the $\mathrm{X}$-ray beam is at right angles to the axis of the X-ray tube. The anode cylinder of this tube is surrounded by a shield, $B$, containing 4 in. of lead shot. The lead cylinder, $D$, immediately in front of the tube target, $A$, contains a monitoring ionization chamber used to check the constancy of the X-ray output. The lead diaphragm in the end of this cylinder limits the X-ray beam to a diameter of approximately $10 \mathrm{~cm}$ at the incident face of the first test specimens, $H$. Immediately in front of this diaphragm there are a 3 -in. lead shutter, $F$, and a series of lead filters, $G$; both the shutter and the filter system are remotely operated from the control room. The test specimens were placed at a distance of from 1 to $2 \mathrm{~m}$ from the tube target. Beyond the specimens a temporary brick wall, $I, 30 \mathrm{~cm}$ thick, was erected in order to reduce the effect of scattered radiation. The $\mathrm{X}$-radiation passes through the aperture in this brick baffle, and after passing through the $4-\mathrm{cm}$ aperture in the diaphragm, $J$, in front of the leadshot baffle, $K$, enters the pressure ionization chamber. The ionization current produced within this chamber is amplified by an FP-54 amplifier and is measured by a potentiometer in the grid circuit of the amplifier. For details relating to the pressure ionization chamber and the ionization measuring system used, reference should be made to the paper by Taylor, Singer, and Charlton describing this apparatus [14].

No filtration was used other than that inherent in the X-ray tube and in the monitoring ionization chamber. This filtration consisted of $0.79-\mathrm{mm}$ brass, $0.79-\mathrm{mm}$ copper, $12.7-\mathrm{mm}$ water, and $1.53-\mathrm{mm}$ aluminum.

The experimental procedure is as follows: One or more of the test specimens are placed in the position indicated in figure 1 , the number used at any one time depending upon the thickness of concrete for which the lead equivalent is desired. In this way, the concrete thickness is increased in steps of approximately $5 \mathrm{~cm}$ to a total sufficient to reduce the dosage rate to $0.35 \times 10^{-5} \mathrm{r} / \mathrm{sec}$ or less for any given quality of radiation. At a given tube voltage and tube current the ionization current is determined by the measuring system described above. The specimens are then removed from the beam, and lead filters are introduced in turn by means of the remotely controlled filter system. This is continued until a combination of lead filters is found for which the ionization current is the same as that observed with the specimen in the beam. The total thickness of lead in the beam is taken to be the lead equivalent of the specimen in question. If no such combination of filters is available, the lead equivalent is found by means of an interpolation curve for lead filters having approximately the lead equivalent of the specimen. To find the thickness ratio in any given case, the thickness of the sample is divided by the thickness of its equivalent lead filter.

For purposes of X-ray protection, the lead equivalent of any sample, and therefore, the thickness ratio, should be determined for barriers of sufficient thickness to reduce the dosage rate of any given beam of radiation incident upon it to approximately $0.35 \times 10^{-5} \mathrm{r} / \mathrm{sec}^{2}$; that is, to such a level that a person may remain behind the barrier continuously for $8 \mathrm{hr}$ and receive no more than $0.1 \mathrm{r}$. When ionization measurements are carried out for barrier thicknesses sufficient to bring about such a reduction in the dosage rate of the incident radiation, scattering effects become important and must be eliminated, if possible, or if not possible, must be corrected for. In order to minimize the effect of scattering when very thick specimens are examined, ionization readings for each specimen and for each lead filter are taken in two steps: (1) as described above, and (2) with a 6 -in. lead plug inserted in the aperture, $L$, in the 6 -in.

\footnotetext{
2 The tolerance dose was defined by The International X-ray and Radium Protection Commission at the Fifth International Congress of Radiology, Chicago, September 1937, as 0.2 roentgen per day, which "on the basis of continuous irradiation during a working day of 7 hours $* * *$ corresponds to a tolerance dosage rate of $10^{-5} \mathrm{r} / \mathrm{sec}$." As more and more penetrating radiation has come into common use in both medicine and industry, a trend has developed toward the reduction of the daily tolerance dose from 0.2 to $0.1 \mathrm{r}$. In both Handbook HB20 of the National Bureau of Standards and in the Industrial X ray Safety Standard of the American Standards Association, the daily tolerance, or permissible dose, is given as $0.1 \mathrm{r}$, which on the basis of continuous exposure throughout an 8 -hr working day is equivalent to approximately 0.2 milliroentgen per minute, or $0.35 \times 10^{-5} \mathrm{r} / \mathrm{sec}$.
} 
baffle, $K$. This second reading is a measure of the scattered radiation entering the pressure chamber. The ionization reading for the specimen or lead filter in question is found by taking the difference between the first and second of these readings.

\section{Results}

\section{Effect of Tube Voltage and Barrier Thickness}

For concrete, the lead equivalent of each specimen was determined for potentials from 400 to $1,400 \mathrm{kv}$ in steps of $100 \mathrm{kv}$. The results so obtained have been plotted in figure 2 to show the lead equivalent of concrete at each of these voltages as a function of the barrier thickness. For the sake of completeness, there has been added to these curves, others based on similar data published earlier by Singer, Taylor, and Charlton [9] for generating potentials between 200 and $400 \mathrm{kv}$. The increasing effectiveness of concrete as a protective barrier with increasing voltage, an effect that is very pronounced in the potential range between 200 and $400 \mathrm{kv}$, is still apparent at $1,400 \mathrm{kv}$, but the rate of this increase falls with increasing potential. For high generating potentials and for thick barriers, the curve showing the lead equivalent of a barrier as a function of its thickness is approximately linear. For low voltages and relatively thin barriers, the curves are parabolic.

In table 1 the results obtained for concrete are summarized for narrow X-ray beams. In the first column the voltage applied to the tube is given; in the second, the ratio of thickness of concrete to thickness of lead giving equivalent protection under identical conditions; in the third, the mass ratio, that is, the ratio of the mass of a concrete barrier to that of a lead barrier affording equivalent protection under identical conditions. In table 2 similar data are given for steel.

As the lead equivalent of a barrier material is not in general proportional to the barrier thickness, the thickness ratios given in the second column of tables 1 and 2 will depend upon the barrier thickness. The thickness of especial interest is that sufficient to reduce the intensity of the $\mathrm{X}$ radiation incident upon it to the "tolerance" or "permissible dosage rate." For the purpose of computing the thickness ratios given in tables 1 and 2, it has been assumed that the barrier in question is such as to reduce to $10^{-5} \mathrm{r} / \mathrm{sec}$ the
X-radiation incident upon it from an X-ray tube $1 \mathrm{~m}$ away when the tube is operated at the potential indicated and at a tube current of $3 \mathrm{ma}$. These factors were selected in order to facilitate comparison of these data with data reported by others for approximately the same conditions. Under other operating conditions, these ratios are still sufficiently accurate for practical purposes, since, as is evident from figure 2 , the lead equiva-

TABLE 1.-Thickness and mass ratios for concrete

\begin{tabular}{|c|c|c|}
\hline $\begin{array}{c}\text { X-ray } \\
\text { energy }\end{array}$ & $\begin{array}{c}\text { Thickness } \\
\text { ratio for } \\
\text { concrete }^{1}\end{array}$ & $\begin{array}{c}\text { Mass ratio } \\
\text { for concrete }\end{array}$ \\
$k v$ & & \\
200 & 355 & 11.4 \\
250 & 334 & 7.1 \\
300 & 324.6 & 5.1 \\
400 & 316.2 & 3.4 \\
500 & 11.5 & 2.4 \\
600 & 9.3 & 1.9 \\
700 & 8.1 & 1.7 \\
800 & 7.1 & 1.5 \\
900 & 6.5 & 1.4 \\
1,000 & 6.1 & 1.3 \\
1,200 & 5.6 & 1.2 \\
1,400 & 5.2 & 1.1 \\
& & \\
\hline
\end{tabular}

1 The thickness ratio is obtained by dividing the thickness of concrete by the thickness of lead required for equal protection under identical conditions.

2 The mass ratio is obtained by dividing the mass of a concrete barrier by the mass of a lead barrier required for equal protection under identical conditions.

These ratios are computed for a concrete barrier of sufficient thickness to reduce a narrow beam of incident radiation to $10^{-5} r / \mathrm{sec}$ at $1 \mathrm{~m}$ from an X-ray tube operated at the voltage indicated and a tube current of $3 \mathrm{ma}$. All data were obtained at the National Bureau of Standards.

${ }^{3}$ G. Singer, L. S. Taylor, A. L. Charlton, J. Research NBS 21, 783 (1938) RP1155.

TABLE 2.- Thickness and mass ratios for steel

\begin{tabular}{|c|c|c|}
\hline $\begin{array}{c}\text { X-ray } \\
\text { energy }\end{array}$ & $\begin{array}{c}\text { Thickness ra- } \\
\text { tio for steel }^{1}\end{array}$ & $\begin{array}{c}\text { Mass ratio } \\
\text { for steel }^{2}\end{array}$ \\
\cline { 1 - 2 }$k v$ & & \\
200 & $13.6[6]$ & 9.4 \\
300 & $7.5[6]$ & 5.2 \\
400 & $4.9[6]$ & 3.4 \\
500 & $3.5[5]$ & 2.4 \\
600 & 2.9 & 2.0 \\
800 & 2.2 & 1.5 \\
1,000 & 1.9 & 1.3 \\
1,400 & 1.7 & 1.2 \\
& & \\
\hline
\end{tabular}

1 The thickness ratio is obtained by dividing the thickness of steel by the thickness of lead required for equal protection under identical conditions.

2 The mass ratio is obtained by dividing the mass of a steel barrier by the mass of a lead barrier required for equal protection under identical conditions.

These ratios are computed for a steel barrier of sufficient thickness to reduce a narrow beam of incident radiation to $10^{-5} \mathrm{r} / \mathrm{sec}$ at $1 \mathrm{~m}$ from an $\mathrm{X}$-ray tube operated at the voltage indicated and a tube current of $3 \mathrm{ma}$. Unless other wise specified the data given are those obtained at the National Bureau of Standards. 
lent of a barrier tends to become linear for barrier thickness of the order required for adequate $\mathrm{X}$-ray protection. For this reason, tables 1 and 2 (and their graphs given in figures 3 and 4, respectively) may be used without appreciable error in computing X-ray protection for various tube currents and distances on the basis of a daily tolerance dose of $01 r\left(0.35 \times 10^{-5} \mathrm{r} / \mathrm{sec}\right)$.

In figure 3 the thickness ratio for concrete has been plotted as a function of the tube voltage that applies. The heavy line through the open circles is that obtained for the data given in table 1 , covering the potential range from 200 to $1,400 \mathrm{kv}$. In the interest of completeness, and for the purpose of comparison, points obtained from the published data of 11 other workers have also been plotted. With the exception of the data taken from Heidenreich and Jeager [4], the agreement between the several workers, although not as close as might be desired, is as good as can be expected when

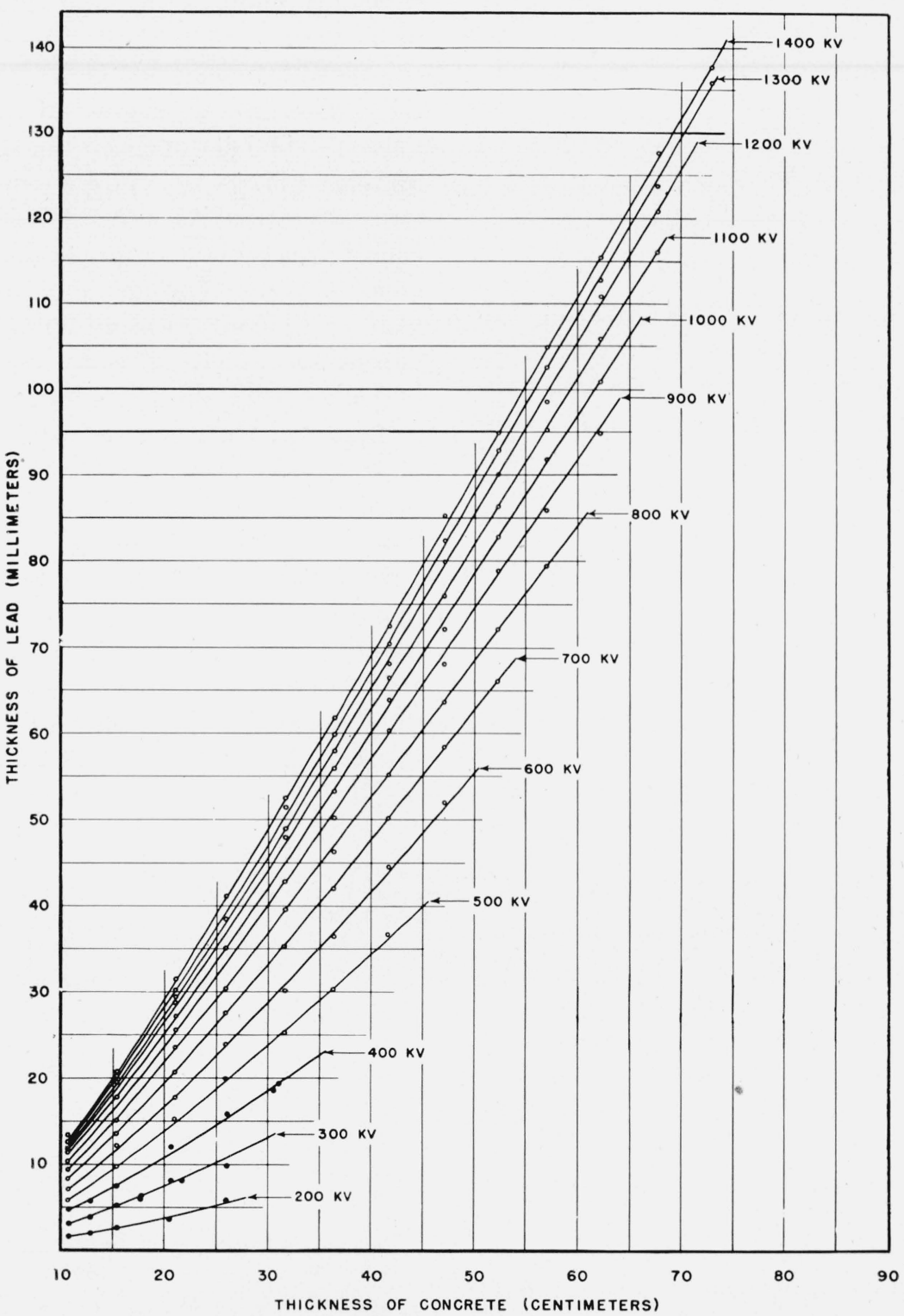

Figure 2.-Variation of lead equivalent of a concrete barrier with barrier thickness for potentials between 200 and $1,400 \mathrm{kv}$.

Lead equivalent of concrete, constant potential; narrow X-ray beam, axis at right angles to axis of electron stream; density of concrete $2.35 \mathrm{~g} / \mathrm{cm}^{3}$. 


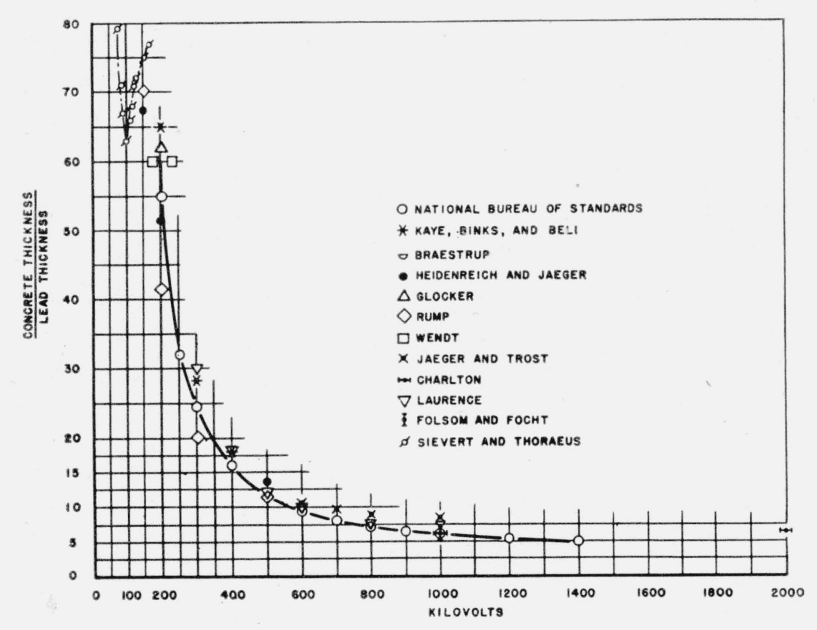

Figure 3.-Ratio of concrete thickness to lead thickness as a function of tube voltage.

Ratio of concrete thickness to lead thickness to reduce radiation at one meter to $10^{-5} \mathrm{r} / \mathrm{sec}$.

consideration is given to all factors affecting the end result. Aside from the errors involved in the making of such measurements--of which only a rough estimate is possible - there are many conditions that are not equivalent for the several determinations. A significant comparison of such data is possible only when the test samples, the nature of the radiation, and the irradiated area are similar, and furthermore only when the accuracy with which these factors are defined can be specified.

Correction for differences in the test specimens is possible whenever their density is specified; likewise, correction for differences in initial dosage rate can be made if the necessary data are supplied. These corrections, being relatively simple to make, were applied to all data plotted in figure 3 for which the necessary information was available. The effect of variations in radiation quality on the results, while very important, is difficult to determine as many operating conditions must be considered in such an evaluation. These include the generator wave form; the accuracy of voltage measurement; the tube bias used, both inherent and controlled; the direction of the X-ray beam with respect to that of the electron stream; filtration; and spectral selectivity of the radiation detector used. While important at all voltages, these factors become increasingly so as the tube voltage is increased. In figure 3 no attempt was made to correct for any of the factors relating to the specification of radiation quality or beam diameter.

The results of all the laboratories clearly show the essential characteristics of protective barriers made of concrete or of similar materials of low atomic number. As already noted, such barriers are comparatively ineffective at low voltages, that is, a greater thickness ratio is, in general, required for soft X-rays than for X-rays of relatively greater penetrating power. Thus, at $200 \mathrm{kv}$ a concrete barrier should be about 60 times as thick as a lead barrier if equivalent protection is to be had, whereas, at $1,000 \mathrm{kv}$, a comparable concrete barrier need be only about six times the thickness of its equivalent lead barrier. The discontinuity in the curve at approximately $100 \mathrm{kv}$ is caused by the $K$-absorption limit of lead. As a result of this discontinuity, such barriers have a minor maximum lead equivalent at this voltage and a minor minimum lead equivalent at approximately $200 \mathrm{kv}$. For potentials above $200 \mathrm{kv}$ the lead equivalent increases (the thickness ratio decreases) rapidly at first and then more slowly as the photoelectric absorption of lead becomes less important, until in the range between 1,000 and $2,000 \mathrm{kv}$ relatively little change is to be observed.

In figure 4 the thickness ratios for steel are plotted to show variation with X-ray generating potential. These data were taken from table 2 . In addition, there is included the thickness ratio of steel at 2,000 $\mathrm{kv}$ computed from absorption

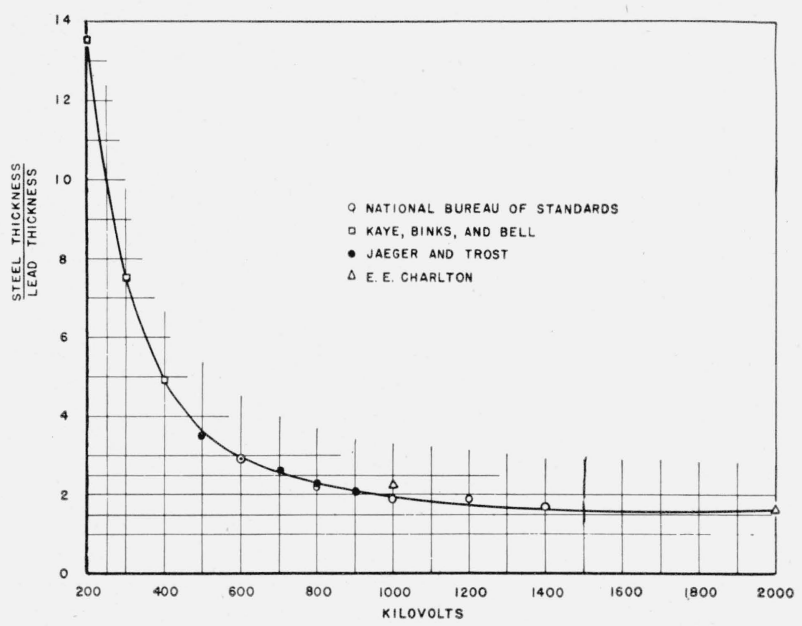

Figure 4-Ratio of steel thickness to lead thickness as a function of tube voltage

Ratio of steel thickness to lead thickness to reduce radiation at one meter to $10^{-5} \mathrm{r} / \mathrm{sec}$. 
curves recently published by Charlton and Westendorp [10]. Except that the thickness ratios for steel are less than for concrete - approximately in the ratio of the densities of the two materials for this potential range - the discussion given in connection with figure 3 applies also to figure 4 .

\section{Effect of X-ray-Beam Diameter}

The lead equivalent obtained for a given test sample depends upon the area of the sample irradiated in making the determination. Materials of low atomic number produce a larger percent of their X-ray attenuation by scattering than does lead whose photoelectric absorption is still appreciable in this potential range. Therefore, when determined for an X-ray beam of large diameter, the lead equivalent of a barrier of relatively low atomic number is less than that obtained when a small beam is used. The use of small fields is desirable because only under such experimental conditions can accurately reproducible data be obtained. This technic is objectionable, however, as a lead equivalent so obtained is not necessarily a true measure of the effectiveness of a given barrier under actual working conditions. When very broad beams are used, the actual lead equivalent of the barrier in question may be much less than indicated by experimental determination involving the use of small X-ray fields. This effect must be guarded against, especially for very penetrating radiation, as the effect becomes greater the more penetrating the radiation becomes. Unfortunately, because of technical difficulties in obtaining such data, there is at present relatively little information available on the effect of beam size.

Of the data on thickness ratios for concrete presented in graphical form in figure 3, only the points taken from the work of Jaeger and Trost [5], and also from Braestrup's [3] paper, were obtained with the broad beams encountered in the application of radiation barriers. The experimental conditions for which the work of Jaeger and Trost was carried out was such that the diameter of the beam is approximately $30 \mathrm{~cm}$. The beam size in Braestrup's work is not specified. The differences between the lead equivalents obtained by these workers and those obtained by the others listed in figure 3 are therefore significant as they give a rough indication of the decrease in the lead equivalent of a barrier when different beam sizes are used.

\section{Mass Ratio for Concrete and Steel}

In the construction of new buildings for housing X-ray installations, the matter of the relative mass of various protective barriers must of course be considered in the design of the building, but this factor is of relatively greater importance when an X-ray installation is to be set up in an old building, in which serious restrictions may be imposed on the additional loading that may be applied to walls, floors, and ceilings without approaching the danger point. For use in connection with the problems of this nature, there is given in figure 5 the mass ratio of both steel and concrete barriers for potentials between 100 and $1,400 \mathrm{kv}$. Here, again, there is shown in addition to the data first reported here, that recomputed from the published work of several other workers in this field. It should be noted that the points for concrete and steel both fall on a single curve. This means that the lead equivalents of barriers

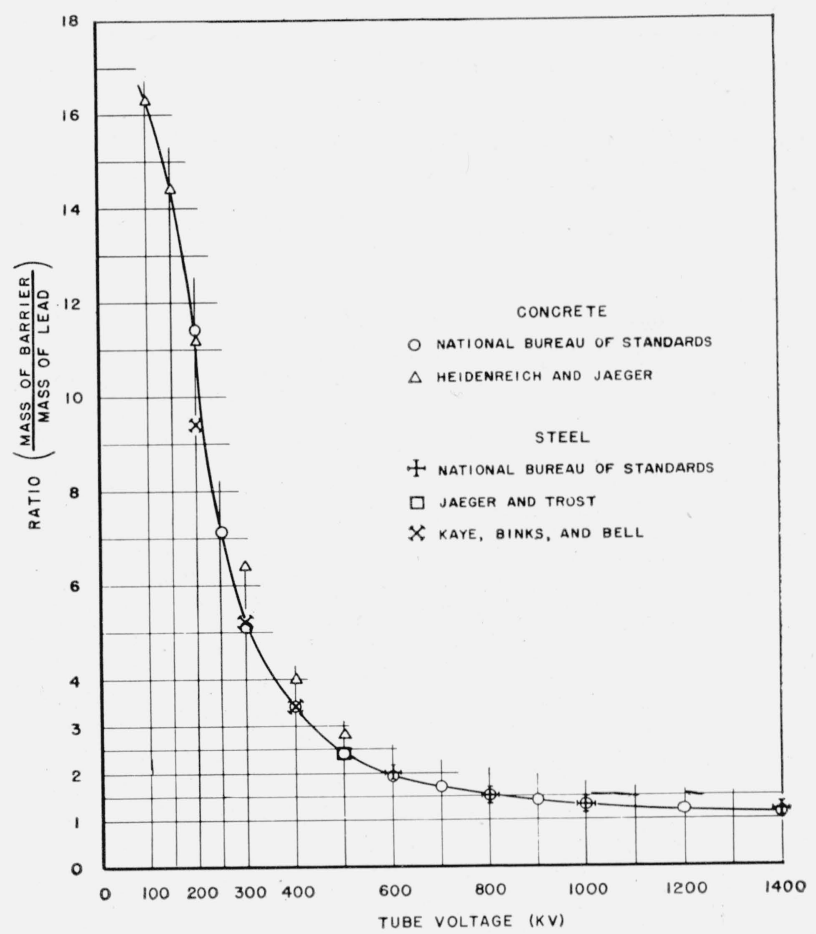

Figure 5-Mass ratio of concrete and steel barriers for potentials between 100 and 1,400 kv

Mass ratio for concrete and steel barriers-narrow X-ray beam. 
constructed of these materials are proportional to their relative densities.

\section{Summary}

Metallic lead is the primary X-ray protective material in the low-voltage range. It has been supplemented by such materials as concrete and steel in the supervoltage range but is unlikely to be entirely superseded. For this reason, the specifications of the relative effectiveness of various materials as protective barriers in terms of metallic lead is of interest. From the data presented herein for lead, concrete, and steel, it is possible to determine the thickness of a barrier of anyone of these materials when that for lead is known. ${ }^{3}$ For potentials up to $250 \mathrm{kv}$, the recommendations of the American Standards Association are available. For X-rays generated by potentials greater than $250 \mathrm{kv}$, limited experimental and theoretical data for absorption curves are available, but there has been no general agreement on these requirements in the supervoltage region, except for the concrete curves for wide angle beams given by the ASA Code. ${ }^{4}$

\footnotetext{
${ }^{3}$ It is necessary that caution be used in such an application for the data given in this paper applies only to the case of narrow beams of $\mathrm{X}$-rays.

4 The National Bureau of Standards has recently completed an experimental arrangement for determination of the effect of the size of the irradiated area of the barrier upon the attenuation produced. It is expected that this information will soon be available.
}

\section{References}

[1] Safety code for the industrial use of X-rays, ASA Z54.1 (American Standards Association, New York, N. Y., 1946).

[2] G. Singer, C. B. Braestrup, and H. O. Wyckoff, J. Research NBS 37, 147 (1946) RP1735.

[3] C. B. Braestrup, Radiology 43, 286 (1944).

[4] Fr. Heidenreich and R. Jaeger, Physik. Z. 39, 541 (1938).

[5] R. Jaeger and A. Trost, Elektrotech. Z. 61, 1025, (1940)

[6] G. W. C. Kaye, W. Binks, and G. E. Bell, Brit. J. Radiol. 11, 676 (1938).

[7] G. C. Laurence, L. W. Ball, and W. J. Archibald, National Research Council of Canada (1942). Personal communication.

[8] R. M. Sievert and Thoraeus, Acta Radiologica 11, 331 (1930).

[9] G. Singer, L. S. Taylor, and A. L. Charlton, J. Research NBS 21, 783 (1938) RP1155.

[10] E. E. Charlton and W. F. Westendorp, Electronics 17, 128 (1944).

[11] E. F. Focht and T. R. Folsom, Am. J. Roentgenol. Radium Therapy 51, 76 (1944).

[12] E. E. Charlton and H. S. Hubbard, Gen. Elec. Review 43, 272 (1940).

[13] Lauriston S. Taylor, BS J. Research 5, 609 (1930) RP217.

[14] L. S. Taylor, G. Singer, A. L. Charlton, J. Research NBS 21, 19 (1938) RP1111.

Washington, September 19, 1946. 